\title{
Sistem Kontrol Pesawat Tanpa Awak Untuk Menentukan Waypoint Berbasis Ardupilot
}

\author{
Putri Rachmawati*, Muhammad Haydar Asyam \\ Teknologi Mesin, Program Vokasi Universitas Muhammadiyah Yogyakarta \\ Jl. Lingkar Selatan, Tamantirto, Kasihan, Bantul \\ *Penulis korespondensi: putri.rachmawati@vokasi.umy.ac.id
}

Histori artikel: diserahkan 20 Maret 2021, direviu 25 Maret 2021, direvisi 27 Maret 2021

\begin{abstract}
An unmanned Aerial Vehicle (UAV) is a type of unmanned aerial vehicle which is controlled by a remote system. This type of aircraft is usually controlled by remote control from outside the plane and can also move automatically based on a program that has been programmed on the computer system. In this study, a control system with autopilot and remote control is used. This study aims to apply the ardupilot system to the super heavy model aircraft with a long-range flight mode control system using the Futaba T8J (8 channel) radio control. The results of this study took a flight time of 15.02 minutes with an altitude of 30 meters, a waypoint radius of 20 meters with a speed of $10 \mathrm{~m} / \mathrm{s}$.
\end{abstract}

Keywords: Unmanned Aerial Vechicle, Ardupilot, Waypoint, APM planner

DOI : https://doi.org/10.18196/jqt.v2i2.11490

WEB : https://journal.umy.ac.id/index.php/qt/article/view/11490

\section{PENDAHULUAN}

Indonesia dikenal sebagai negara agraris. Lahan Indonesia yang dikenal dengan kesuburannya, sehingga hasil tanam apapun jenis tanamannya bisa tumbuh. Karena kesuburan tanah tersebut, masyarakat Indonesia banyak yang bekerja sebagai petani. Berdasarkan catatan BPS menyebutkan luas lahan sawah Indonesia tahun 2019 sebesar 7,1 juta hektar. Luasnya lahan pertanian di Indonesia, walaupun semakin berkurang di tiap tahunnya, akan tetapi masih banyak masyarakat Indonesia yang mata pencahariannya sebagai petani. Petani terkadang kesulitan saat menebar benih ketika lahan tersebut jauh dari pemukiman seperti; pegunungan, lereng, ataupun dekat dengan pantai, karena alat yang dimiliki masih traditional sehingga memerlukan sentuhan teknologi supaya petani dapat memudahkan saat menyebar benih lahan petanian dalam skala besar.

Berdasarkan permasalahan tersebut, tercipta suatu teknologi inovatif untuk membantu petani menyebar benih pertanian dengan sistem pesawat tanpa awak untuk menentukan koordinat pada lahan. Pesawat terbang tanpa pengendali maupun tanpa awak dan tanpa pilot biasa dinamakan dengan pesawat tanpa awak atau pesawat UAV (Unmanned Aerial Vehicle).

Pesawat ini biasa dikendalikan dengan menggunakan remote control atau disebut dengan (RPV) Remote Piloted Vehicle melalui jarak jauh, sehingga pesawat UAV dapat terbang berjalan dengan cara otomatis sesuai dengan program yang sudah diterapkan pada sistem perangkat keras (Rahman et al., 2018). Pengunaan pesawat ini terbesar adalah bidang militer, akan tetapi semakin berkembang bisa digunakan dalam berbagai bidang (Wijaya \& Sugiharto, 2019).

Pesawat jenis ini mempunyai sistem kontrol dengan 2 Tipe, yaitu (1) Tipe pengendali jarak jauh; dan (2) Tipe pesawat yang terbang secara mandiri berdasarkan program yang 
diterapkan ke dalam sistem pesawat sebelum beroperasi atau terbang. Operasional dalam sistem kontrol ini mengacu pada parameter parameter yang telah ditentukan oleh pengguna sebelum terbang dengan kendali sepenuhnya oleh autopilot.

Proses kontrol pesawat bisa menggunakan radio control (RC) (Frasiska, Budiastra, \& Pratolo Rahardjo) adalah sebuah perangkat yang dimana penggunaanya untuk mengontrol dan mengendalikan dari pergerakan suatu pesawat UAV.

Teknologi autopilot digunakan pada pesawat bisa diterapkan pada kendaraan darat maupun laut dalam penerapannya sangatlah mudah dan tepat. Sistem kendali jarak jauh menggunakan GPS (Global Positioning System) pada pesawat maupun kendaraan lain sangat membantu pengemudi saat melakukan aktivitas dimanapun berada. (Devionita, 2020)

Teknologi ini yang biasa dinamakan dengan pengendara udara dengan sistem otomatis adalah sistem mekanikal elektrikal yang bisa memandu sebuah kendaraan tanpa campur tangan dari manusia, sehingga sering dinamakan dengan autopilot. Proses pendaratan pada pesawat tanpa awak merupakan kegiatan yang kompleks karena membutuhkan energi potensial dan kinetik yang cukup banyak dari pesawat terbang yang terdapat beberapa kendala seperti cuaca, arah udara bergerak, kecepatan, berat muatan di setiap gerakan arah pesawat (Muhammad, 2009)

Proses pendaratan pada pesawat tanpa awak membutuhkan tenaga bertautan dengan beberapa tenaga lain, seperti energi potensial dan kinetik yang terkandung harus banyak dari pesawat khususnya, kendala yang di dapat paling besar kecepatan setiap arah dengan pengaruh mendadak berat muatan dan tingginya kecepatan. (Saroinsong et al., 2018).

Menurut Nugroho et al., 2017 pesawat dengan ukuran kecil bisa dijangkau dengan tangan dengan pengendalian memakai remote control, radio waves dengan pengendali manusia dari darat sering disebut aeromodelling. Tujuan dari pesawat ini adalah untuk pembelajaran aerodinamika, model miniatur sebelum dibuat pesawat sesuai dengan skala riil. Beberapa manfaat dari pesawat jenis ini adalah memberikan kemudahan terhadap biaya rendah dengan tingkat resiko yang lebih safety. Berkenaan dengan design pada penerbangan jenis pesawat ini sudah dikembangkan sejak lama dan lebih aman untuk penentuan waypoint.

Menurut Nurtyawan et al., 2016 dalam empat tahun terakhir berbagai jenis piranti tanpa awak telah digunakan oleh kalangan sipil dan ilmiah. Piranti tersebut dilengkapi dengan berbagai macam peralatan untuk memberikan data dan aplikasi, salah satunya pesawat UAV yang fenomenal khususnya pada aplikasi indra jauh. Pesawat ini sangat menarik dengan menggunakan kendali melalui gelombang radio sehingga memerlukan sistem kendali jarak jauh.

Penentuan signal dan titik point pada rute yang akan dituju pada arah tersebut perlu untuk ditandai yang biasa disebut juga waypoint. Waypoint adalah suatu point yang terdapat pada GPS yang sudah ditandai berupa titik lokasi berdasarkan koordinat sumbu lintang (Y) dan bujur (X). (Zaky et al., 2018). Penentuan waypoint ini sangat berfungsi pada GCS (Ground System Control) untuk controller pada sistem computer di pesawat.

Penelitian ini bertujuan untuk menentukan rute koordinat lahan sehingga bisa dengan mudah dalam menebar benih pada lahan pertanian. Dapat memberikan manfaat bagi peneliti untuk keberlanjutannya bisa diterapkan bagi petani yang ada di lereng gunung maupun di pesisir pantai dengan mudah dalam menebar benih di lahan pertanian.

\section{Metode Penelitian}

Penelitian ini dilakukan Kampus Universitas Muhammadiyah Yoogyakarta dan di lokasi persawahan Godean, Sleman Yogyakarta dengan mengambil titik koordinat rute data untuk menebar benih tanaman.

Penelitian ini di mulai dengan perancangan sistem pesawat tanpa awak pada model super heavy dengan langkah sebagai berikut :

1. Pengumpulan data dan komponenkomponen yang akan digunakan 
2. Merancang hardware dan perangkat lunak (software) dari sistem pesawat.

3. Perakitan hardware dan pembuatan program dari pesawat tanpa awak, memasang autopilot sesuai dengan spesifikasi pesawat model superheavy, kemudian memasang GPS yang harus terhubung dengan autopilot.

4. Pemilihan wireless Telemetry untuk pengendali jarak jauh dengan mengkalibrasi pada perangkat keras yang terhubung oleh autopilot kemudian pemasangan Ground Control Station (GCS).

5. Singkronasi sistem kontrol pesawat tanpa awak yaitu terkoneksinya autopilot, GPS, Wireless Telemetry, Ground Control System (GCS).

6. Analisa apakah sistem kontrol tersebut sudah bekerja dengan baik dan akurat. Apabila telah bekerja sesuai dengan yang diinginkan, kemudian membuat Kesimpulan.

Alur langkah penelitian yang dilakukan dapat dilihat pada Gambar 1.

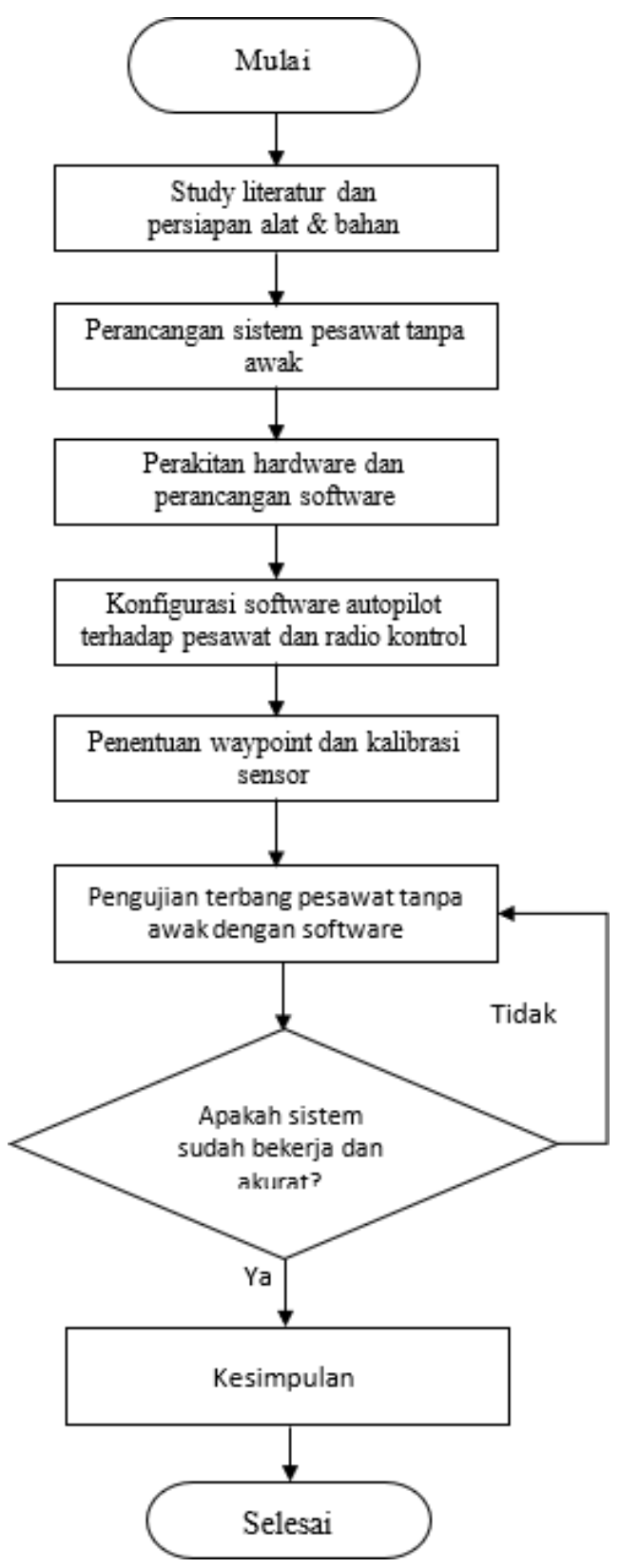

GAMBAR 1. Alur Penelitian

\section{HASIL DAN PEMBAHASAN}

Sistem kontrol pesawat tanpa awak model fly wings. Dapat dilihat pada Gambar 2.

Komponen di dalam pesawat pada gambar 2, sebagai berikut:
1. Arduflyer dan GPS (Global Positioning System) 


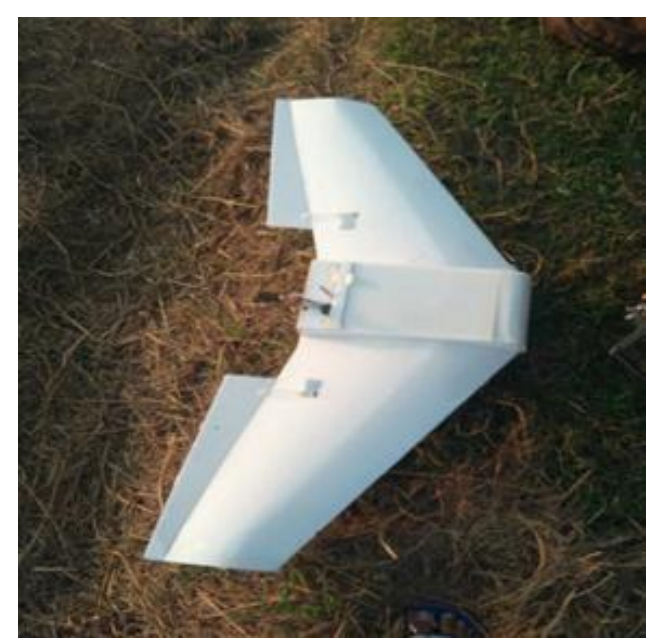

GAMBAR 2. Pesawat model fly wings

Arduflyer merupakan jenis flight controller dengan dimensi $6.6 \mathrm{~cm}$ x $4.4 \mathrm{~cm}$. Arduflyer type 2.5 penempatan badan pesawat tanpa mengubah kontruksi pesawat, karena dilengkapi dengan port koneksi GPS dan telemetri (Gambar 3).

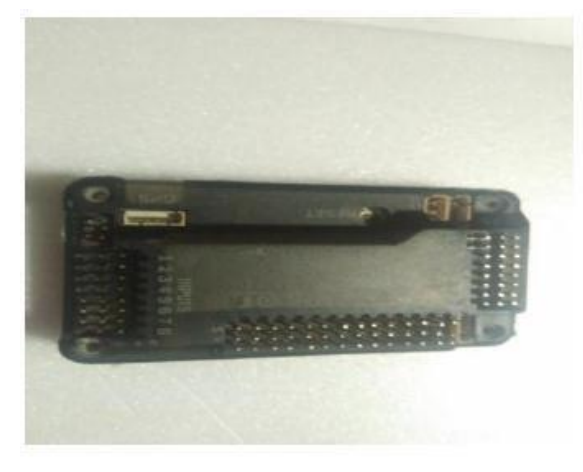

\section{GAMBAR 3. Arduflyer dengan GPS yang terpisah}

Pengertian GPS yaitu media atau alat pemandu arah yang dapat mengidentifikasi lokasi pesawat Ketika terbang dengan menyesuaikan spesifikasi arduflyer 2.5. GPS yang digunakan pada perancangan ini adalah Crius CN-06. Jenis ini merupakan standard GPS yang mampu bekerja langsung terhadap satelit tanpa membutuhkan jaringan internet. Jenis ini memiliki antenna berukuran $25 \times 25 \mathrm{~mm}$ yang kompatibel terhadap arduflyer 2.5 (Gambar 4) dan skema proses GPS pada pesawat (Gambar 5).

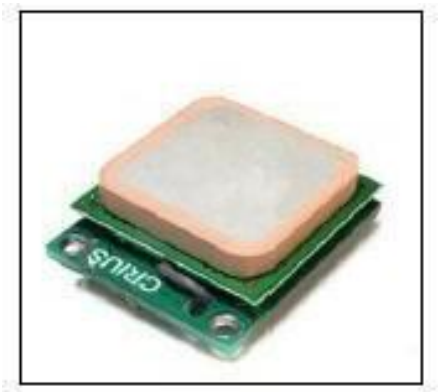

GAMBAR 4. GPS Crius CN-06

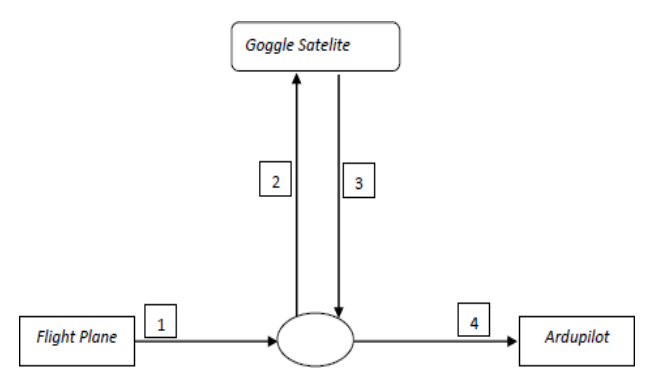

GAMBAR 5. Proses GPS pada pesawat

\section{Wireless Telemetry}

Wireless telemetry ini berfungsi untuk mengirim dan menerima data dengan jangkauan luas dan stabil.

\section{Ground Control Station (GCS)}

Ground control station (GCS) merupakan software yang digunakan pada perancangan ini berupa source software yaitu mission planner, sehingga sanggup dalam menayangkan data pesawat, melihat peta digital dan memiliki fitur dalam parameter pesawat. Ditunjukkan pada Gambar 6 dan Gambar 7.

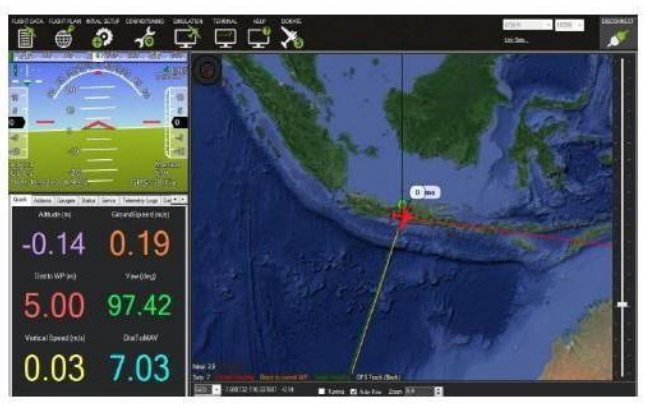

GAMBAR 6. Tampilan software mission planner 


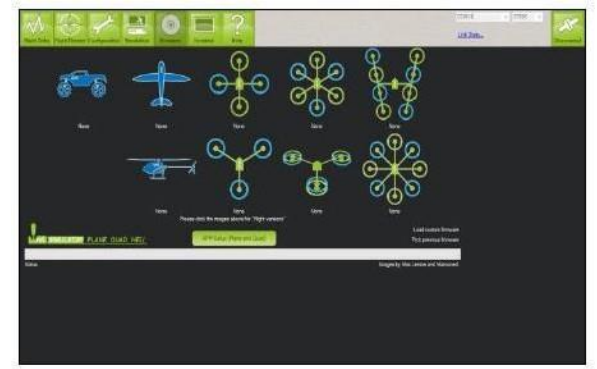

GAMBAR 7. Konfigurasi jenis kendaraan model pada mission planner

\section{Perangkat sistem $U A V$}

Pemasangan perangkat sistem UAV dimulai dengan ardupilot, power module, perancangan GCS, penyambungan GCS terhadap pesawat, koneksi dengan wireless telemetry, pengecekan GPS dan kalibrasi radio control, seperti pada Gambar 8.
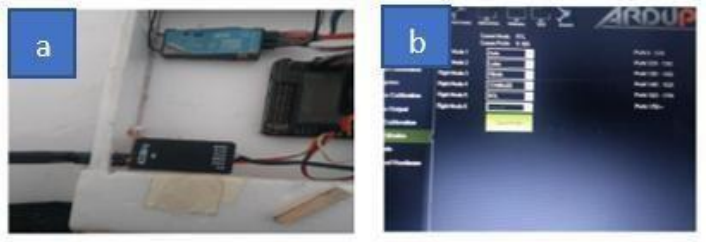

GAMBAR 8. (a) flight control system UAV; (b) flight mode pada autopilot
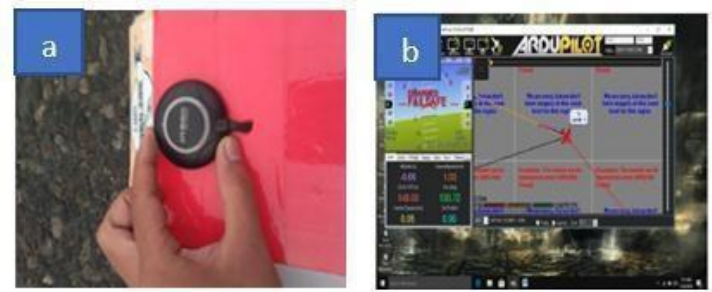

GAMBAR 9. (a) GPS module pada pesawat; (b) GCS telemetry pada jarak 450 - 500meter

Pengujian pada penelitian ini melakukan uji terbang supaya dapat mengetahui semua komponen dan perangkat sudah bekerja dengan baik, serta terpasang sempurna sehingga mampu menerbangkan pesawat UAV secara mandiri. Pengujian terbang memberikan waypoint sebagai jalur penerbangan pesawat seperti pada Gambar 9. Ketinggian $30 \mathrm{~m}$ dengan jarak waypoint $20 \mathrm{~m}$ dengan rute simple dibutuhkan waktu tempuh 05.12 menit.

Berdasarkan pemilihan bahan dari pesawat, menurut Shomad et. al. (2020) pemilihan material yang ringan seperti komposit sebagai komponen pesawat tanpa awak akan berpengaruh terhadap uji terbang.

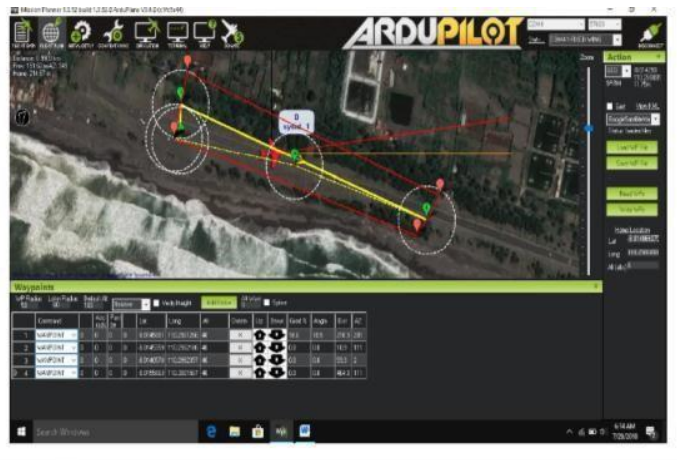

GAMBAR 10. Waypoint pengujian sistem pesawat model UAV

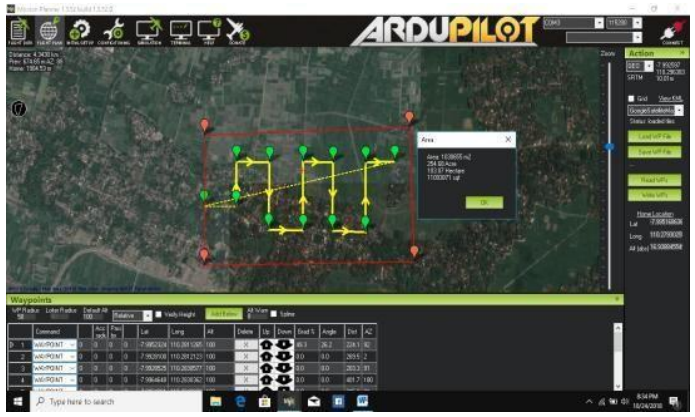

GAMBAR 11. Waypoint rute pesawat area persawahan

Uji terbang pertama melakukan evaluasi dari hasil uji yaitu terdapat permasalahan pada telemetry module dengan gagal jaringan saat melakukan manuver dengan rute yang mengarah ke laut karena uji pertama di lahan pertanian dekat dengan pantai. Permasalahan kedua saat landing keras karena saat rute mendekati home point, flight mode digantikan dengan manual mode, pesawat tidak respon, sensor autopilot tidak merespon sistem ardupilot terdapat kendala.

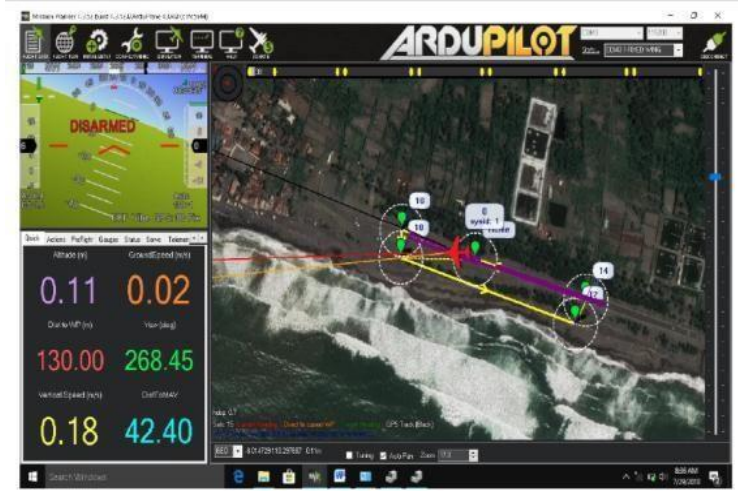

GAMBAR 12. Hasil rute yang telah dilalui 
Pada Gambar 12 merupakan hasil uji terbang menggunakan sistem autopilot, dengan hasil yang ditunjukkan terdapat garis berwarna ungu pada flight plane waypoint dimana pesawat berhasil terbang melalui rute yang sudah dilalui pesawat menggunakan sistem autopilot.

Hasil pengujian penerbangan pada penelitian ini dapat dilihat pada Tabel 1 .

TABEL 1. Hasil uji penerbangan pada pesawat dengan sistem autopilot

\begin{tabular}{|c|c|}
\hline Uji terbang & Hasil penerbangan \\
\hline Uji terbang 1 & $\begin{array}{l}\text { Pesawat mengalami } \\
\text { kegagalan tidak } \\
\text { terkoneksinya } \\
\text { telemetry dan GPS } \\
\text { belum bisa terbang }\end{array}$ \\
\hline Uji terbang 2 & $\begin{array}{l}\text { Pesawat terbang belum } \\
\text { mengalami } \\
\text { keseimbangan aileron } \\
\text { dan elevator dalam } \\
\text { terbang, dikarenakan } \\
\text { ada } \\
\text { komponen } \\
\text { sehingga } \\
\text { kehilangan gas pada } \\
\text { throttle }\end{array}$ \\
\hline Uji terbang 3 & $\begin{array}{l}\text { Pesawat berhasil } \\
\text { terbang dengan } \\
\text { autopilot tetapi sedikit } \\
\text { kendala pada respon } \\
\text { sinyal mission planner } \\
\text { karena ada komponen } \\
\text { arduflyer yang missing } \\
\text { eror }\end{array}$ \\
\hline Uji terbang 4 & $\begin{array}{l}\text { Pesawat sudah berhasil } \\
\text { terbang dengan } \\
\text { sempurna, } \\
\text { beban yang terlalu } \\
\text { berat pada pesawat } \\
\text { sehingga servo pada } \\
\text { pesawat sempat tidak } \\
\text { mengangkat. }\end{array}$ \\
\hline
\end{tabular}

Hasil pengujian pada Tabel 1. menunjukkan bahwa sistem autopilot tidak akan berfungsi jika pesawat belum siap terbang dengan stabil sehingga sensor pada arduflyer tidak terbaca karena komponen autopilot beresiko cepat rusak terutama pada bagian kabel dan port yang merupakan komponen kecil dan mudah putus.

\section{KESIMPULAN}

1. Pesawat menggunakan 4 titik waypoint tetapi pesawat bisa terbang dengan autopilot pada 2 titik waypoint, dengan ketinggian 30meter, radius waypoint 20 meter dengan kecepatan $10 \mathrm{~m} / \mathrm{s}$, misi penerbangan selesai waktu 05.12 menit, home point berada ditengah rute, falisave tidak menggunakan return to lunch tetapi menggunakan manual mode dan flight mode yang digunakan adalah manual mode, autopilot dan stabilize.

2. Remote control yang digunakan adalah jenis Futaba T8J channel C menggunakan 47\% rate dengan UP, MID dan Down.

\section{UCAPAN TERIMA KASIH}

Ucapan terima kasih disampaikan kepada D3 Teknologi Mesin, Program Vokasi, Universitas Muhammadiyah Yogyakarta dan segenap mahasiswa D3. Teknologi mesin yang telah menyelesaikan penelitian ini.

\section{DAFTAR PUSTAKA}

Devionita, S. 2020. Rancang Bangun Kontrol Pergerakan Posisi Kapal Dengan Sistem Waypoint Berbasis Gps Menggunakan Metode Pid. Media Elektrika, 13(2), 89-99.

Frasiska, I. G. F., Budiastra, I. I. N., \& Pratolo Rahardjo, S. Sistem Pesawat Tanpa Awak Menggunakan Kamera Thermal Untuk Membantu Pencarian Korban Bencana Alam. Jurnal Spektrum, 7(4), 100-107.

Muhammad, F. A. 2019. Rancang Bangun Model Pesawat Tak Berawak Untuk Kebutuhan Pemetaan Udara (Biaya Produksi, Perawatan Dan Perbaikan). Politeknik Negeri Sriwijaya,

Nugroho, G., Agung, B. M., Setiawan, B., \& Wiratama, C. 2017. CFD simulation of the end plates effect on the Elang Caraka Unmanned Aerial Vehicle $(U A V)$. Paper presented at the 2017 
International Conference on Advanced Mechatronics, Intelligent Manufacture, and Industrial Automation (ICAMIMIA).

Nurtyawan, R., Saepuloh, A., Budiharto, A., \& Wikantika, K. 2016. Modeling surface roughness to estimate surface moisture using radarsat-2 quad polarimetric SAR data. Paper presented at the Journal of Physics: Conference Series.

Saroinsong, H. S., Poekoel, V. C., \& Manembu, P. D. 2018. Rancang Bangun Wahana Pesawat Tanpa Awak (Fixed Wing) Berbasis Ardupilot. Jurnal Teknik Elektro Dan Komputer, 7(1), 73-84.

Shomad, M. A., Yudhanto, F., \& Anugrah, R. A. 2020. Manufaktur dan Analisa Kekuatan Tarik Komposit Hybrid Serat Glass/Carbon untuk Aplikasi Pembuatan Blade Turbin Savonius. Quantum Teknika: Jurnal Teknik Mesin Terapan, 2(1), 47-51.

Wijaya, T., \& Sugiharto, A. 2019). Sistem Auto Take Off, Auto Pilot, Auto Landing, dan RTH pada Pesawat Tanpa Awak (UAV) Fakultas Teknologi Informasi dan Elektro Universitas Teknologi Yogyakarta. University of Technology Yogyakarta.

Zaky, M., Mufti, A., \& Rahman, A. 2018. Perancangan Sistem Kendali Berbasis Gps (Global Positioning System) Pada Kapal Tanpa Awak. Jurnal Karya Ilmiah Teknik Elektro, 3(2). 